\title{
English Teaching and Learning under Network Background
}

\author{
Lihua Chen ${ }^{1, a^{*}}$ \\ ${ }^{1}$ Department of foreign languages and affairs, Wuhan city vocational college, wuhan,430064,China \\ aemail: meredithshen@163.com
}

Keywords: Network; Teaching model; Constructivist teaching english.

\begin{abstract}
The rapid development of the Internet to optimize foreign language teaching and learning environment with meters boundless vitality and hope, not only its advantage lies in its wealth of learning resources, but also in opening up to the English learners - of mutual learning, exchange and learn from the vast world. English teaching really did go out on E books, taken the classroom, to the world, so that the teaching content of the virtual real, static to dynamic, abstract to concrete. Foreign Language Teaching in Network Environment is contemporary foreign language teaching theory and practice as a guide to the development and application of modern information technology as the basis, combined with the characteristics of English subjects teaching reform carried out. This paper introduces the basic theory of teaching mode, be pointed out the advantages of English teaching in network environment, presented in a network environment, Constructivism and the communicative approach guided by "student-centered, teacher-led "English teaching model.
\end{abstract}

\section{Introduction}

With the development of information technology in education and promoting quality education, multimedia and network technology based on modern educational technology reform has become the main focus of educational research [1-3]. Information technology, breaking the traditional teaching time, place many restrictions, teaching methods, teaching resources, to our teaching theories, methods and models brought great impact. At the same time, constructivism and CLT has become the guiding ideology of English teaching field [4]. Synchronous interactive multimedia technology, especially network technology provided by the asynchronous interaction, situational creation, negotiation sessions and vast amounts of information resources, it is required constructivist learning theory learning environment must have the basic elements of the popularity of multimedia and network technology, but also for the realization of constructivist learning environment provides the best conditions $[5,6]$.

Teaching English website provides listening, grammar, writing and other training, students can exchange information with each other through, participate in the discussion, immediate language testing, training and other means to learn writing [7]. Electronic publication is an online electronic magazine specifically for English teaching, in addition to providing various levels of reading, writing, listening test, comprehensive test and various language learning materials, but also includes academic articles, research papers, teaching design, teaching methods and other guidance learners from the Internet every day to learn new knowledge $[8,9]$. Open the famous VOA, CNN, BBC and other sites, teachers and students can watch online the most timely news stories, understand the dynamic world and learn authentic English and improve the use of the language skills. In addition there are a large number of interconnection line English teaching aids software for teachers and students English teaching English learning are of great help [10].

The network is assisted English reading teaching approach combines reading courses own characteristics and student-centered autonomous learning environment, not restricted by time and place, the students become the main teaching. Plus the application of multimedia and network technology, teachers can make the task of teaching the novel and lively, to stimulate student interest. Specific steps we network assisted English reading teaching is: Reading Upload creative teachers - 
students read online, a complete assessment of teachers' work, online Q\&A. Selection is network-assisted teaching of reading is extremely important part, the creative content should not exist in isolation from the classroom. To close the classroom content, into a ring of teaching content; the selection arrangement to gradually increase the difficulty, so that students have a sense of competence, to stimulate students' self-confidence; you want to add some reading material related to the theme of the article pictures, comics, animation, jokes, film clips, to increase reading interest. Our platform provides network-assisted teaching of reading - and a wide range of space so that teacher-student interaction, student town to the Internet to read the content question, teachers to students answering questions online.

\section{Basic Theory of Teaching Model}

Development of network technology is not completely negate the traditional teaching methods and models, but in the new environment of traditional teaching methods and models and integrated innovation. In the teaching mode network environment, the teaching theory, teaching environment, teaching strategies and teaching process are four key elements. Teaching mode under the guidance of certain teaching theory generated, teaching theory is the soul of Teaching. Reform of teaching information line was shown in Fig. 1.

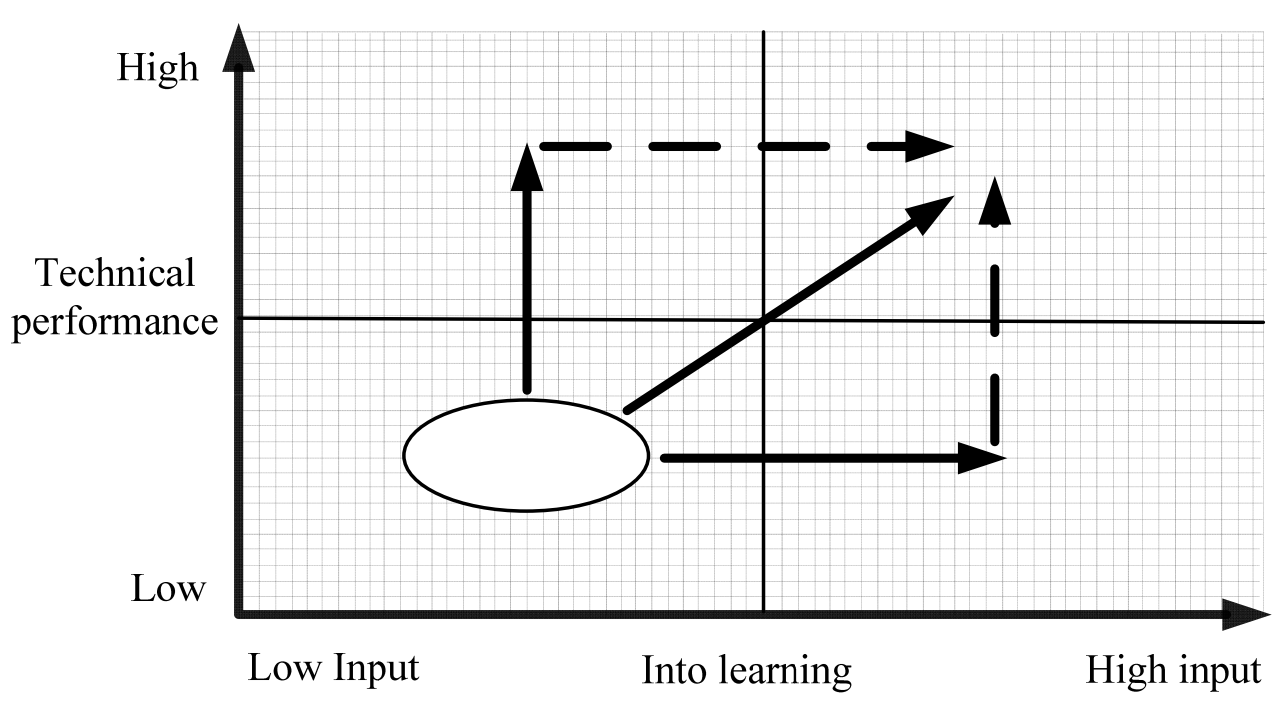

\section{Reform of teaching information line}

Figure 1. Reform of teaching information line

The teaching process (Fig. 2) is the implementation of specific steps teaching behavior, the teaching process is the rational combination of all aspects. Teaching strategy is to achieve the purpose of teaching methods and means, the key issues related to the teaching process, the choice of methods, the use of the media to guide the study of law, evaluation and feedback. In the traditional mode of teaching, teaching environment is not the critical part, and in the network environment, teaching environment determines the smooth implementation of the teaching process, and can even break through the traditional environmental constraints, the traditional teaching model in the new environment It produced a new meaning. Therefore, we must consider the network environment as a key element in the teaching model designed to treat. 


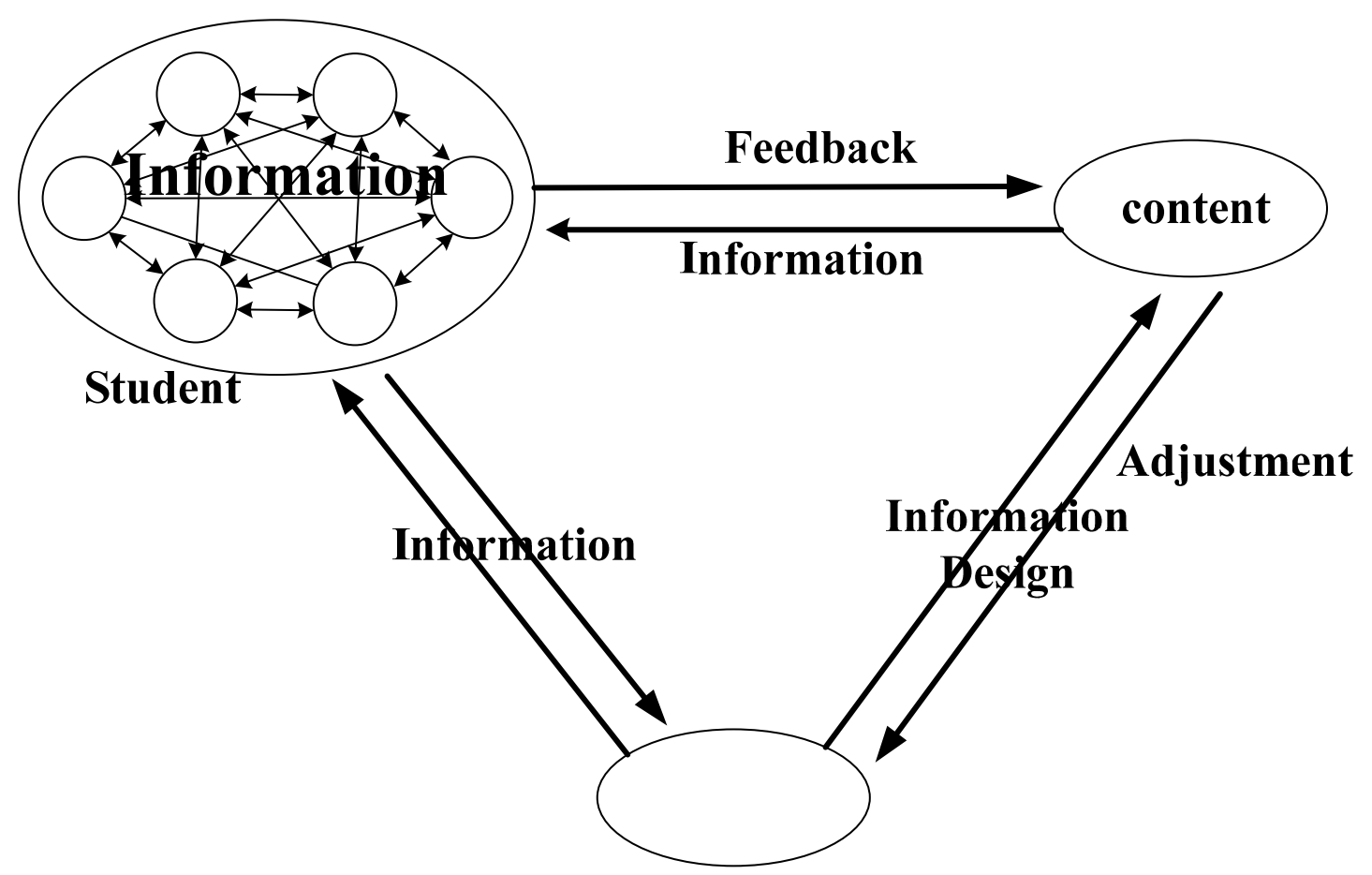

Figure 2. Basic Theory of Teaching Model

The traditional mode of teaching theory, teaching mode can be divided into "teacher-centered" and the "student-centered," the two types. "Teacher-centered" teaching model is mainly lecturing; and "student-centered" and it can be divided into the "self-centered" and "group-centered." "In the individual-centric" include: self-counseling mode, discovery learning model, case studies and other types of models; the "group-centric" include: discussion of learning, collaborative learning mode type.

\section{Foreign Language Teaching Mode under the Network Environment}

In the network environment should be combined with network information teaching characteristics and features of English subjects, Constructivism and the communicative approach as a guide, give full play to the initiative and creativity of students, to stimulate students' interest in learning English, students process information, innovation, communicative ability and comprehensive ability to use language. This section Constructivism and the communicative approach as a guide for English teaching mode under network environment to try to put forward a comprehensive teaching model (see Figure 1), the model adhere to the "teacher-led, student-centered" to task the problem, as the core of the case. Teachers give full play to the advantages of network technologies situational creation, organize, direct teaching, students make full use of network resources, to take the initiative to study independently, communicate and collaborate language exercises.

Traditional instructional design, teaching goal is above all, it is both the starting point of the teaching process, but also the fate of the teaching process. By analyzing the order of teaching objectives teaching content and teaching content arrangements needed can be determined; teaching goal is to check the final assessment of teaching effectiveness and teaching basis. Constructivism requirements "student-centered" learning, in fact require individualized teaching. Scenes and instructional design issues inclusive learning goals and should be slightly higher learner itself existing experience and knowledge and ability, so that students have the interest and confidence in problem-solving activities proactively activate your original experience through active, systematic reasoning activities, completion of the new, old interaction experience. This must be based on knowledge of the structure and type of in-depth analysis on this, problems and tasks can be a good 
cover teaching objectives defined body of knowledge, according to the different types of knowledge, learning content embedded constructivist environment the different elements.

Teachers must analyze learner's knowledge base, cognitive ability and other mental factors and interest, motivation, emotion, will and personality and other non-intelligence factors for students to design a personality problem scenarios and learning resources. Carried out in the network environment of teaching, in particular, should consider students basic computer ability, if poor students computer skills, English teaching might be adversely affected. Before using the network teaching English, it should be tested, if students lack the necessary computer skills and basic Internet knowledge, skills and training should be relevant to students knowledge of the network. Teaching flow was shown in Fig. 3.

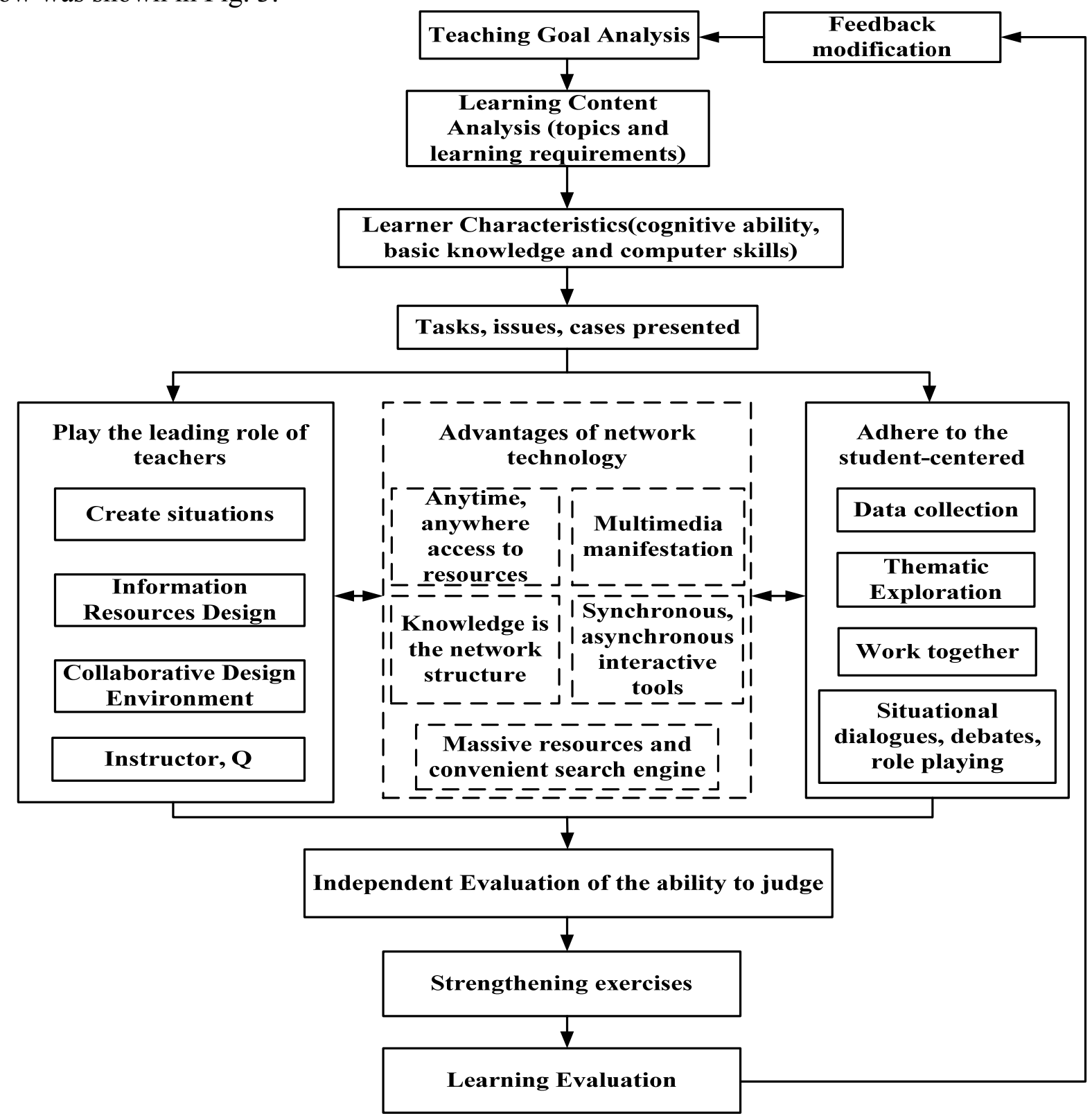

Figure 3. Teaching flow

In language teaching, grammar, vocabulary and other basic knowledge is the basis for the formation of an integrated language skills, can not be completely ruled out in teaching teachers on language knowledge. However, we can use the train network environment integrated into the language knowledge points to the "student-centered" teaching process, so as to ensure balanced development of students' language fluency, accuracy and complexity. In designing this task, teachers should make it clear to the students should use words, phrases, or grammar, the purpose is to enable students to focus on the language forms. In teaching, tasks, issues, cases can be presented in various 
forms, such as the use of streaming media publishing listening materials, with real live video showing scenes of real life, or animation problem situations, using BBS published cases, the use of electronic post messages personalized issues and so on.

\section{Summary}

English Teaching is communicative approach and constructivism requirements, the development of multimedia and network technology, foreign language learning to students autonomous provide a broad, flexible and creative learning space for the realization of this model provides a practical environment. In the actual teaching process, teachers should be innovation, learning a foreign language acquisition theory and the latest multimedia and network technology knowledge, while adhering to the student center on the basis of full teacher organizer, facilitator, helper, guide's role. Teachers can coursework the students formative assessment, evaluation is the main content of the students 'knowledge level, whether the meaning construction requirements, in addition, should also pay attention to the students' self-learning ability, the ability to ask questions, understanding, collaboration as well as the ability to communicate, etc. comprehensive evaluation in the evaluation of student performance, it should be advisory, and should not be results-oriented and mandatory.

\section{References}

[1] Lei V L C, Zhou I J, He Y. Large-corpus-based Cognitive Study of Translation and Interpreting Processes: Methodological Procedures and Theoretical Implications[J]. 2014.

[2] Liang Y. Research of Multimedia Interactive English Teaching Evaluation System under Network Environment[J]. International Journal of Advancements in Computing Technology, 2013, 5(2).

[3] Juan Z. On Translating Chinese Internet Buzzwords into English from the Perspective of Skopos Theory: Taking the Example of 2012 Chinese Internet Buzzwords[J]. Journal of Hubei Engineering University, 2013, 2: 017.

[4] Chen H. Research on Literary Translation Capability and the Construction of Training Mode[C]//2015 International Conference on Education Technology and Economic Management. Atlantis Press, 2015.

[5] Hao Y. Explicitation of Personal Pronoun Subject in Chinese EFL Majors' Translation: A Case Study of Translation Universals Based on PACCEL-W[J]. Journal of Language Teaching and Research, 2015, 6(3): 669-678.

[6] Underwood P R. Teacher beliefs and intentions regarding the instruction of English grammar under national curriculum reforms: A Theory of Planned Behaviour perspective[J]. Teaching and Teacher education, 2012, 28(6): 911-925.

[7] ZHOU Y, WANG Y. Theoretical basis and strategy selections for the English translation of traditional Chinese medical terms from 1981 to 2010[J]. China Journal of Traditional Chinese Medicine and Pharmacy, 2013, 4: 042.

[8] Liu H Y, You X F, Wang W Y, et al. The development of computerized adaptive testing with cognitive diagnosis for an English achievement test in China[J]. Journal of Classification, 2013, 30(2): 152.

[9] Celik S. Internet-assisted technologies for English language teaching in Turkish universities[J]. Computer Assisted Language Learning, 2013, 26(5): 468-483.

[10]Mestan K, Harvey A. The higher education continuum: access, achievement and outcomes among students from non-English speaking backgrounds[J]. Higher Education Review, 2014, 46(2). 